\title{
Continuous Distribution
}

National Cancer Institute

\section{Source}

National Cancer Institute. Continuous Distribution. NCI Thesaurus. Code C53213.

A statistical distribution described by a function whose range may assume any value, typically any value in the set of real numbers. 